\title{
Pengurusan Wakaf Pendidikan di Institusi Pengajian Tinggi Malaysia: Satu Sorotan Literatur
}

\author{
Najibah Mustaffa ${ }^{\text {** }}$, Mohd Zamro bin Muda \\ Jabatan Syariah, Fakulti Pengajian Islam, Universiti Kebangsaan Malaysia, 43600 Bangi, Selangor \\ *Corresponding author:an_nuwairah05@yahoo.com
}

\author{
Article history \\ Received: 2014-05-28 \\ Received in revised form: 2014-09-16 \\ Accepted: 2014-10-26
}

\begin{abstract}
The article discusses the literature review, whether in the form of research, books, articles, etc. on the issue of the management, challenges and the way forward of waqf in higher education institutions in Malaysia.The study was conducted using qualitative methods by taking a literature study approach. There has been a lot of writing, throwing ideas and discussions were made by the experts, academician and governments on the issue. Waqf of education in Malaysia is seen growing with the establishment of waqf fund for education in several institutions such as the International Islamic University Malaysia (IIUM), Universiti Putra Malaysia (UPM), Universiti Kebangsaan Malaysia (UKM), Universiti Sains Islam Malaysia (USIM), Universiti Teknologi Malaysia (UTM) and many more. The literature review found that the development of waqf in higher education can be intensified by effective fund management, strong legislation, good governance, marketing efforts and identify appropriate waqf management model to be applied. A special guideline for the management is to be established and a waqf management model is designed to be used as a reference all the Heigher Education Institutions.
\end{abstract}

Keywords: Endowments (waqf), education, management of waqf, institutions of higher education.

\begin{abstract}
Abstrak
Wakaf pendidikan sudah lama diamalkan di Malaysia dengan wujudnya institusi pendidikan berbentuk tradisi seperti pondok, madrasah, sekolah agama rakyat dan sekolah agama negeri. Pada tahun 1999, Universiti Islam Antarabangsa Malaysia (UIAM) telah menubuhkan IIUM Endowment Fund menjadikannya institusi pengajian tinggi (IPT) pertama di Malaysia yang menubuhkan tabung wakaf pendidikan. Perkembangan ini diikuti oleh beberapa buah IPT lain dari tahun ke tahun. Artikel ini membincangkan satu perkembangan penulisan, sama ada dalam bentuk penyelidikan, buku, artikel dan sebagainya dalam membahaskan isu pengurusan, cabaran dan masa depan wakaf pendidikan di institusi pengajian tinggi di Malaysia. Kajian ini dilakukan dengan menggunakan metode kualitatif dengan mengambil pendekatan kajian kepustakaan. Hasil sorotan literatur yang dilakukan, boleh dikatakan bahawa telah banyak penulisan, lontaran idea dan perbincangan mengenai wakaf pendidikan dibuat oleh para sarjana, ahli akademik dan juga pihak kerajaan. Wakaf pendidikan di Malaysia dilihat semakin berkembang dengan penubuhan tabung wakaf pendidikan di beberapa buah IPT seperti Universiti Islam Antarabangsa Malaysia (UIAM), Universiti Putra Malaysia (UPM), Universiti Kebangsaan Malaysia (UKM), Universiti Sains Islam Malaysia (USIM), Universiti Teknologi Malaysia (UTM) dan beberapa buah lagi. Hasil sorotan literatur mendapati pelaksanaan wakaf pendidikan di IPT boleh diperhebatkan perkembangannya dengan pengurusan dana yang berkesan, perundangan yang kukuh, urustadbir yang baik, pemasaran yang diperhebatkan dan mengenalpasti model pengurusan wakaf yang sesuai untuk diaplikasikan. Satu garis panduan khas bagi pengurusan wakaf pendidikan di IPT perlu diwujudkan dan satu model pengurusan wakaf dirangka untuk dijadikan rujukan semua IPT.
\end{abstract}

Kata kunci: Wakaf, pendidikan, pengurusan wakaf, institusi pendidikan 


\subsection{PENGENALAN}

Kos untuk membiayai pendidikan semakin mahal berikutan yuran pengajian semakin meningkat terutama bagi kursus-kursus kritikal dalam bidang sains dan teknologi seperti perubatan, sains kesihatan, farmasi, kejuruteraan, sains angkasa dan lain-lain. Tidak terkecuali juga bidang sastera dan agama yang merupakan bidang tradisi bagi majoriti pelajar Bumiputera Muslim (Abdul Halim Sunny, 2007). Kos pendidikan semakin hari dijangka semakin meningkat seiring dengan kenaikan harga barang dan perkhidmatan di Malaysia. Institusi pengajian swasta berlumba-lumba menawarkan peluang pendidikan kepada pelajar yang mencapai keputusan peperiksaan kurang cemerlang namun dengan mengenakan yuran pengajian yang agak tinggi dan membebankan pelajar.

Di saat kos pendidikan yang begitu tinggi dan menghimpit golongan berpendapatan rendah, kedengaran idea pendidikan percuma yang diketengahkan oleh manisfesto Pakatan Rakyat (PR) ketika menghadapi Pilihan Raya Umum ke-13 yang lalu (Sinar Harian Online, 2014) disambut dengan pelbagai reaksi dan persepsi oleh masyarakat. Jika pendidikan percuma ini dapat dilaksanakan, ini akan melegakan hati ramai ibubapa di Malaysia. Walau bagaimanapun, timbul persoalan sejauhmanakah idea pendidikan percuma ini dapat dilaksanakan? Apakah mekanisme yang boleh digunakan untuk menampung kos pengajian yang semakin hari semakin meningkat? Pinjaman PTPTN dilihat tidak mampu menangani masalah peningkatan kos ini kerana menurut laporan, seramai 412,245 daripada 1.24 juta peminjam tidak membayar balik pinjaman sehingga 31 Ogos 2013 (Sinar Harian Online, 2013). Kemunculan pelbagai produk takaful dan insurans yang menawarkan caruman pendidikan untuk anak-anak dan juga penubuhan Tabung SSPN beberapa tahun kebelakangan ini memperlihatkan kepada kita bahawa tidak dapat tidak usaha perlu dilakukan bagi menangani masalah peningkatan kos pendidikan di Malaysia hari ini. Dengan tidak menafikan bahawa usaha menabung adalah sesuatu yang baik dan bermanfaat, artikel ini cuba meninjau sorotan literatur sejarah dan perkembangan pengurusan wakaf pendidikan di Malaysia, dan bagaimana pembiayaan pendidikan melalui instrumen wakaf yang kini mula dilaksanakan di beberapa buah IPT di Malaysia boleh menjadi satu solusi kepada latar belakang permasalahan yang dinyatakan di atas.

Islam agama yang syumul dan sentiasa memberi solusi kepada setiap permasalahan ummah telah menjadikan wakaf sebagai salah satu mekanisme pembiayaan pendidikan. Sejak zaman permulaan Islam iaitu pada awal abad ke-7, pendidikan ketika itu telah pun dibiayai oleh wakaf dan sumbangan sukarela daripada masyarakat. Meskipun ada pembiayaan oleh kerajaan bagi tujuan pendidikan seperti pembinaan sekolah dan infrastruktur lain, namun wakaf tetap menyalurkan pendapatan yang konsisten untuk membiayai kos operasi sekolah-sekolah tersebut. Sebagai contoh, sepertimana Wakaf Ayubites (11711249) dan Wakaf Mamalik (1249-1517) di Palestin, Syria, Lubnan dan Mesir yang merupakan contoh wakaf pendidikan yang berjaya (Monzer Kahf, t.t). Peranan wakaf tradisional dalam sejarah kegemilangan Islam membuktikan bahawa ianya banyak digunakan untuk memenuhi keperluan hidup masyarakat Islam. Dana wakaf pernah digunakan untuk membina infrastruktur besar awam seperti jalan raya, jambatan, hospital dan bekalan air, sama ada untuk minuman atau untuk saliran pertanian. Wakaf juga pernah digunakan untuk mendanai kemudahan perkapalan, perbekalan dan pengangkutan jemaah haji dan umrah, selain sebagai dana untuk membantu kebajikan golongan miskin dan yang memerlukan bantuan. Malah lebih dari itu, pernah dicatatkan bahawa dana wakaf turut digunakan untuk memberi makan serigala dan binatang liar di hutan supaya tidak menyerang manusia dan dengan demikian kehidupan mereka terlindung dari diancam oleh manusia (Muhammad Ali Hashim, 2012).

Institusi sosial masyarakat Islam seperti pendidikan atau madrasah dan masjid juga banyak dibiayai oleh pendapatan harta wakaf. Pembiayaan ini meliputi perbelanjaan mengurus dan pembangunan institusi berkenaan seperti membina, membaiki bangunan, membayar gaji pekerja seperti guru, imam, muazzin dan sebagainya. Wakaf dilihat bukan sahaja berfungsi sebagai mekanisme pengagihan semula kekayaan tetapi juga untuk memperkukuhkan keupayaan individu dan masyarakat yang memerlukan bantuan asas seperti modal pinjaman, rawatan hospital, makanan berkhasiat, keperluan infrastruktur dan sebagainya. 
Kemuncak kehebatan amalan wakaf zaman silam adalah pada zaman Khilafiah Uthmaniyyah yang disimpulkan seperti berikut (Razali Othman, 2005):

"Seseorang dilahirkan dalam rumah yang diwakafkan, tidur dalam buaian yang diwakafkan, membaca buku-buku yang diwakafkan, mengajar dalam sekolah yang diwakafkan, menerima gaji dari pentadbiran wakaf, dan akhirnya apabila ia mati kelak, urusan jenazahnya adalah atas pentadbiran wakaf dan ia dikuburkan dalam tanah perkuburan wakaf.”

Sabda Rasulullah S.A.W yang bermaksud (Al-San'ani, 1979):

"Apabila mati seseorang manusia, habislah amalnya (tidak bertambah lagi kebaikan amalnya itu) kecuali tiga perkara; sedekah jariyah, ilmu yang bermanfaat, dan anak yang soleh yang mendoakan kedua ibubapanya”

\section{(Hadis Riwayat Muslim)}

Pembiayaan institusi pendidikan melalui mekanisme wakaf dapat memenuhi tiga komponen yang dimaksudkan dalam hadis di atas iaitu sedekah (wakaf), ilmu yang berguna dan anak yang soleh. Ketigatiga perkara tersebut dapat disempurnakan melalui wakaf dalam institusi pendidikan sebagaimana yang difahami dan dihayati oleh ulama (Ahmad Zaki Latiff et. al, 2008).

\subsection{METODOLOGI KAJIAN}

Kajian ini secara teorinya merupakan kajian yang bersifat kualitatif, iaitu kajian yang mengadaptasi metode pengumpulan data melalui penganalisisan kandungan dokumen. Pengumpulan data kajian melalui kajian kepustakaan yang mana rujukan dibuat kepada sumber primer dan sekunder melibatkan kitab-kitab turath sebagai rujukan utama berkaitan wakaf, dan juga sumber lain seperti buku, jurnal, artikel, kertas persidangan, seminar, kertas penyelidikan, tesis, keratan akhbar, carian di internet dan seumpamanya sama ada dalam Bahasa Melayu, Bahasa Arab dan Bahasa Inggeris.

\subsection{WAKAF MENURUT ISLAM}

Istilah wakaf tidak dinyatakan secara langsung di dalam al-Quran atau al-hadith. Wakaf berasal dari bahasa Arab (waqafa) yang bermaksud berhenti (al-sakn) (Ibn Manzur, 1990), menahan (al-habs), menegah (al-man') (Al-Sarakhsi, 1986) dan menyalurkan (tasbil) (Ali Gom‘ah, 2012). Wakaf juga mempunyai berbagai-bagai makna lain mengikut tujuan dan penggunaan ayat itu sendiri. Ulama fiqh sepakat mentakrifkan wakaf mengikut istilah bahasa dengan al-habsyang beerti menahan; kerana perkataan al-habs itu lebih hampir kepada pengertian syarak (Asmak, 2009).

Perkataan 'ditahan' di atas membawa erti bahawa sesuatu harta yang diwakafkan (dipanggil mawquf) tidak boleh dilibatkan dalam mana-mana transaksi atau pindah milik seperti dijual, dicagar dan sebagainya. Seseorang penerima wakaf (dipanggil mawquf 'alayh) hanya boleh memanfaatkan harta berkenaan tanpa mempunyai hak pemilikan penuh terhadapnya. Justeru, pemilikan ini hanya boleh dikategorikan di bawah 'pemilikan tidak sempurna' (milk al-naqis) kerana harta wakaf diiktiraf sebagai milik Allah atau pada hukum milik Allah dan pewakaf hanya menyedekahkan manfaatnya ke arah kebajikan dari mula hingga akhirnya (Asmak, 2009).

Dalam perundangan Islam pula, ada beberapa perkataan yang digunapakai merujuk kepada wakaf. Dalam kalangan Mazhab Maliki di Utara dan Barat Afrika (termasuk Morocco, Algeria dan Tunisia) wakaf disebut sebagai hubus. Manakala di Perancis sebagai habous (Fayzee, 1974), boniyad di Iran, waqf di negara-negara Arab, vaqf di Turki, wakap di Java dan wakaf di Malaysia (Siti Mashitoh, 2006). Meskipun berbeza istilah yang digunakan, ianya tetap membawa maksud yang sama iaitu wakaf ialah suatu bentuk penyerahan atau dedikasi harta, sama ada secara terang (sarih) atau sindiran (kinayah) yang 
mana harta berkenaan ditahan dan boleh digunakan tanpa susut fizikalnya (Mustafa, 2005) dan hanya manfaatnya sahaja yang diaplikasikan kepada tujuan-tujuan kebajikan sama ada berbentuk umum mahupun khusus (Ibn Qudamah, 1972).

Konsep wakaf sebenarnya tertumpu kepada pembekuan atau pemegangan aset yang diwakafkan dan penyaluran manfaat mawquf berkenaan untuk digunakan bagi faedah benefisiarinya. Ditinjau dari sudut pemilikan aset berkenaan, wakaf dianggap sebagai terhak kepada Allah SWT. Konsep ini menekankan bahawa pewakaf dan aset yang diwakafkan tidak mempunyai sebarang hubungan lagi selepas sesuatu kontrak pewakafan diwujudkan. Dengan ini seseorang pewakaf tidak mempunyai hak untuk menjalankan apa-apa transaksi terhadap aset yang diwakafkan. Konsep ini juga didapati memenuhi kriteria penting sesuatu pewakafan iaitu elemen kekal di dalamnya.

\subsection{BEZA WAKAF PENDIDIKAN DENGAN WAKAF-WAKAF LAIN}

Di dalam Islam, tujuan wakaf boleh dikategorikan kepada tiga iaitu wakaf bagi tujuan keagamaan (religious waqf), wakaf kekeluargaan (family waqf) dan wakaf kebajikan (philantrophic waqf) (Monzer Kahf, t.t). Wakaf keagamaan yang pertama dalam sejarah Islam ialah pembinaan Masjid Quba' di Madinah oleh Nabi Muhammad SAW ketika ketibaan baginda di Madinah dalam peristiwa hijrah. Masjid tersebut masih kekal binaannya ditempat yang sama dengan pembaharuan dan pembesaran struktur masjid. Kemudiannya, enam bulan selepas hijrah, Masjid Nabawi pula dibina di tengah-tengah kota Madinah.

Kategori kedua wakaf berdasarkan tujuan pewakafannya ialah wakaf untuk keluarga. Wakaf kategori ini bermula tidak lama selepas kewafatan Nabi Muhammad SAW, iaitu ketika era pemerintahan Khalifah Umar Al-Khattab (635-645 Masihi). Ketika Umar ingin mendokumenkan wakaf yang dibuat oleh beliau di Khaibar, beliau menjemput beberapa orang sahabat Nabi Muhammad SAW untuk mengesahkan dokumen tersebut. Salah seorang sahabat bernama Jabir yang memberitahu ada dalam kalangan pemilik hartanah apabila membuat wakaf, mereka meletakkan syarat bagi pendapatan wakaf di mana diberikan kepada anak-anak dan keturunan terlebih dahulu, kemudian selebihnya barulah diberikan kepada orangorang miskin.Wakaf ini dinamakan sebagai wakaf keluarga. Ini berbeza dengan pengamalan Yayasan di Amerika Syarikat yang menghadkan endowmen hanyalah bagi tujuan keagamaan atau kebajikan sahaja.

Kategori ketiga ialah wakaf kebajikan atau juga disebut sebagai philanthropy waqfyang bertujuan untuk membantu orang-orang miskin dan menyumbang kepada apa sahaja aktiviti yang memberi manfaat kepada masyarakat awam seperti pembinaan perpustakaan, pusat penyelidikan, pusat pendidikan, perkhidmatan kesihatan, penjagaan haiwan dan persekitaran, memberi pinjaman kepada peniaga-peniaga kecil, kemudahan taman, jalanraya, jambatan, dan sebagainya. Wakaf pendidikan yang dibincangkan dalam artikel ini termasuk dalam kategori ini.

Institusi pendidikan wakaf merupakan institusi pendidikan yang ditubuhkan atau dibina dengan menggunakan harta yang telah diwakafkan oleh umat Islam. Pendidikan pula merupakan satu proses aktiviti berterusan yang mengandungi unsur-unsur pengajaran, latihan, bimbingan, pimpinan dengan tumpuan khas kepada pemindahan berjenis ilmu, nilai agama dan budaya serta kemahiran yang berguna yang dibukukan oleh satu generasi kepada generasi yang lain atau oleh seorang individu kepada individu yang memerlukan (Ahmad Zaki Latiff, 2008). Wakaf dan pendidikan bukanlah sesuatu yang asing dalam Islam. Masjid merupakan antara institusi pendidikan wakaf terawal sebagaimana yang berlaku sejak zaman Nabi Muhammad S.A.W). Masjid Quba' merupakan masjid yang diasaskan sendiri oleh Baginda sewaktu tiba di Kota Madinah pada tahun 622M diikuti dengan pembinaan Masjid Nabawi dan institusi pendidikan wakaf lainnya di zaman awal Islam (Mohd Afendi, 2011). 
Sejak abad ke-17, banyak aktiviti pendidikan dibiayai oleh wakaf dan sumbangan sukarela. Konsep wakaf pendidikan ini telah melahirkan institusi-institusi pengajian yang berkekalan serta melahirkan ribuan ulama yang terkenal dan tersohor di seluruh dunia (Mohamad Akram Laldin, 2012). Antaranya ialah Universiti Cordova di Andalus, al-Azhar di Mesir, Madrasah Nizamiyah di Baghdad, Universiti Islam Indonesia, Pondok Pesantren Darunnajah, Indonesia, Madrasah Al-Junied, Singapura, al- Jamiah alIslamiah di Madinah dan lain-lainnya (Ahmad Zaki Latif et.al, 2008).

Kehebatan institusi wakaf Islam ini adalah diakui sehingga ditiru oleh Barat dengan menjenamakan semula wakaf ke dalam bentuk yayasan, trust atau endowment.Universiti seperti Oxford dan Cambridge di Britain serta Harvard dan Standford di Amerika Syarikat antara universiti berasaskan endowmen dan mempunyai dana yang kukuh. Universiti Harvard misalnya dilaporkan antara universiti terkaya dengan memiliki aset endowmen bernilai melebihi US\$30 bilion. Konsep wakaf (endowment fund) ini telah menjadi pemacu kepada kemajuan Barat terutama dalam bidang pendidikan dan perubatan (Ali Gom'ah, 2012). Dana daripada philantrophic waqf untuk membantu golongan miskin dan kemaslahatan ummah seperti kemudahan awam, pendidikan, kesihatan, kerja-kerja penyelidikan, dan perpustakaan dilihat mempunyai peranan dan potensi yang cukup besar dalam membiayai program pendidikan (Monzer Kahf, 2003).

\subsection{SOROTAN LITERATUR}

Isu berkenaan wakaf di Malaysia telah lama dibincangkan oleh sarjana perundangan, ahli akademik dan profesional di Malaysia meliputi aspek perundangan, pembangunan, pengurusan, dan sebagainya. Perbincangan tersebut secara umumnya membantu ke arah pengupayaan wakaf sebagai instrumen kewangan Islam yang maju dan berdaya saing dalam memantapkan ekonomi ummah dan melahirkan modal insan yang berkualiti. Secara umumnya pelbagai masalah dalam pembangunan wakaf yang telah dikenal pasti antaranya pengurusan yang tidak seragam, kekangan sumber kewangan, masalah kekurangan tenaga profesional yang berkelayakan, tidak mempunyai pangkalan data dan rekod harta wakaf yang lengkap, dan lokasi harta wakaf yang tidak strategic. Pengurusan dan pentadbiran harta wakaf ini seharusnya dibuat secara profesional kerana ini adalah salah satu daripada instrumen ekonomi Islam yang telah terbukti berkesan kepada umat Islam sebelum ini (Ramli, 2005).

\subsection{Perkembangan Wakaf Pendidikan di Malaysia}

Sejarah wakaf pendidikan di Malaysia bermula daripada institusi pendidikan tradisional berorientasikan agama seperti Sekolah Agama Rakyat (SAR), Sekolah Agama Negeri (SAN), madrasah dan pondok (Asmak, 2009). Dalam sistem pengajian Islam tradisional di Malaysia, orang Islam menyerahkan tanah mereka untuk membina sekolah agama. Kemudian ia semakin berkembang apabila orang Islam menyerahkan harta mereka untuk membina tempat tinggal untuk guru-guru. Boleh dikatakan wakaf pendidikan tradisi, bentuk aset wakafnya adalah berkisarkan tanah, rumah, masjid, bangunan, buku dan seumpamanya (Hisham Sabri, 2007). Wakaf pendidikan tradisi ini mulai berkembang di mana telah wujud permintaan wakaf bagi tujuan pendidikan bagi memenuhi keperluan sekolah agama bersepadu di Johor Bharu (Mohd Jelani, 1998). Perkembangan ini adalah signifikan kerana kajian mendapati pembiayaan pendidikan melalui instrumen wakaf dapat mengurangkan masalah keciciran dan ketinggalan anak-anak bangsa yang tidak dapat meneruskan pengajian atas alasan kemiskinan. Terdapat empat faktor penentu kejayaan pelaksanaan wakaf untuk pendidikan iaitu kesedaran masyarakat, keadaan demografi iaitu populasi penduduk Islam yang tinggi, kedudukan ekonomi yang mantap yang dimiliki oleh umat Islam, dan tadbir urus yang cekap dan profesional (Abdul Halim Sunny, 2007).

Perkembangannya semakin rancak di mana wakaf pendidikan tidak lagi semata-mata berkisarkan kepada penyediaan pusat pendidikan pondok, madrasah, sumbangan buku atas nama sistem pendidikan tradisional dan sekolah, malahan ia turut melibatkan institut pengajian tinggi awam dan swasta, antaranya 
Universiti Islam Antarabangsa Malaysia (UIAM) yang menubuhkan IIUM Endowment Fund pada tahun 1999 (Laman Web IIUM, 2014), Universiti Kebangsaan Malaysia (UKM) dengan Dana Waqaf dan Endowmen UKM pada tahun 2010 (Laman Web UKM, 2014), Universiti Putra Malaysia (UPM) dengan Dana Wakaf Ilmu UPM pada tahun 2012 (Laman Web UPM, 2014), dan yang terbaru adalah Universiti Sains Islam Malaysia (USIM) pada tahun 2013 dengan nama Dana Wakaf Al-Abrar (Laman Web USIM, 2014). Malahan terdapat beberapa buah IPT lain juga yang turut menubuhkan tabung wakaf pendidikan di institusi mereka. Penubuhan dana wakaf ini secara umumnya bertujuan untuk menerima aset,wang tunai, saham, dan aset-aset kewangan dalam negara dan luar negara yang akan digunakan untuk membiayai biasiswa, pinjaman dan urusan pengembangan dana seperti aktiviti pelaburan. Universiti Antarabangsa AlBukhari (AiU) di Kedah pula adalah contoh institusi pengajian tinggi swasta di Malaysia yang dibiayai oleh dana wakaf sepenuhnya. Malahan, ketika kajian ini dilakukan, universiti wakaf pertama di Malaysia iaitu Universiti Islam Malaysia (UIAM) telah ditubuhkan di bawah naungan Majlis Raja-Raja Melayu berpusat di Cyberjaya (Utusan Online, 2012). Universiti tersebut telah pun mula beroperasi dan Yang diPertuan Agong Tuanku Abdul Halim Mu'adzam Shah telah diperkenankan oleh Majlis Raja-Raja untuk dilantik sebagai Canselor yang pertama (Utusan Online, 2014). Perkembangan ini dilihat cukup baik dan selaras dengan hasrat kerajaan untuk meningkatkan kualiti modal insan di Malaysia.

Berbeza dengan peringkat awal kewujudan wakaf pendidikan di Malaysia yang bertujuan untuk memberi manfaat kepada bidang pendidikan Islam sahaja, perkembangan mutakhir ini memperlihatkan adanya saranan bagi mewujudkan wakaf pendidikan yang dapat memenuhi pelbagai disiplin ilmu khususnya dalam bidang perubatan. Hal ini bagi manfaat pelajar yang bakal bergelar pengamal perubatan. Wakaf perubatan juga dapat membantu pesakit yang tidak berkemampuan dari sudut kewangan, khususnya pesakit kronik yang memerlukan dana segera bagi tujuan pengubatan (Norsiah, 2009). Usaha merancakkan wakaf pendidikan ini turut disambut baik oleh syarikat korporat seperti Johor Corporation Berhad (JCorp) menerusi anak syarikatnya iaitu Waqaf An-Nur Corporation Berhad (WANCorp) yang telah menjalankan pelbagai projek untuk menjana harta wakaf terutama dalam sektor korporat di mana pulangan daripada wakaf tersebut digunakan antaranya bagi tujuan pendidikan dan pembangunan modal insan melalui agihan manfaat Fisabilillah (Abd. Shakor, 2011). Antara program yang telah dijalankan oleh WANCorp dalam aspek pendidikan dan pembangunan modal insan ialah penajaan program di peringkat IPT seperti konvensyen mahasiswa, sumbangan kepada persatuan pelajar, pembangunan jiwa pelajar seperti SMART Solat, bantuan fasiliti persekolahan, dan banyak lagi (Laporan Tahunan WANCorp, 2013).

\subsection{Cabaran dan Saranan Terhadap Pengurusan Wakaf Pendidikan di Malaysia}

Wakaf merupakan satu instrumen yang amat berkesan dalam membiayai bidang pendidikan. Malangnya, ia masih belum dimanfaatkan sepenuhnya termasuklah dalam mengangkasakan pengajian tinggi. Di antara aspek yang perlu ditingkatkan dalam wakaf pendidikan ialah mengenai aspek pengurusannya. Tanpa pengurusan yang baik dan berhemah, maka wakaf tidak mampu berdaya saing dan mencapai objektifnya dalam menjadi instrumen penjana ekonomi umat Islam. Mufti Mesir, Prof. Dr. Ali Gom'ah (2012) dalam kertas kerja beliau yang dibentangkan dalam Seminar Wakaf Menjana Ekonomi pada 16 Julai 2012 di Putrajaya menyebut:

"Hal ehwal wakaf di Mesir akhir kurun ke 19 hingga awal kurun ke 20, telah diabaikan hingga kedudukan wakaf itu lemah, malah menjadi beban kepada Azhar"

Pelbagai cabaran dihadapi dalam membangunkan institusi pendidikan wakaf di negara ini. Ahmad Zaki Latif et.al (2005) antara yang terawal mengkaji mengenai pengurusan institusi pendidikan wakaf di Malaysia. Walau bagaimanapun, kajian tersebut memfokuskan kepada institusi pendidikan peringkat rendah dan menengah dan berlatarbelakangkan Pendidikan Islam sahaja. Dapatan kajian tersebut menyenaraikan lima cabaran yang dihadapi oleh institusi pendidikan wakaf di Malaysia iaitu pentadbiran, 
sumber kewangan, tenaga pengajar, maklumat, dan pemasaran yang boleh menjadi satu titik tolak perbincangan mengenai cabaran pengurusan institusi pendidikan wakaf yang menjadi fokus artikel ini. Sorotan literatur ini meninjau pelbagai saranan yang dikemukakan oleh pengkaji samada daripada latarbelakang akademik mahupun perundangan bagi menambahbaik pengurusan wakaf pendidikan di Malaysia.

Pengurusan kewangan atau pun dana wakaf merupakan tulang belakang kepada kejayaan sesebuah institusi pendidikan wakaf. Tiga perkara utama yang perlu diberi perhatian dalam pengurusan dana wakaf pendidikan di IPT ialah penyaluran dana bagi tujuan pembangunan fizikal, kos operasi dan program kecemerlangan akademik (Syed Mohd Ghazali, 2012). Institusi pendidikan terutamanya institusi pendidikan tinggi sepatutnya sudah boleh berdikari dan tidak seharusnya bergantung kepada geran dan bantuan kerajaan dalam menguruskan operasi mereka (Mohamed Azam et.al, 2012). Mengambil contoh pengurusan endowmen di Amerika Syariat, mereka menggunakan empat jenis model bagi membangunkan pendidikan tinggi. Model tersebut menggunakan sepenuhnya pengurusan konsultasi, melantik syarikat luar bagi mengendali dana dan menggunakan latihan dalam pejabat untuk menguruskan dana endowmen ini. Setiap universiti yang mempunyai dana endowmen yang digunakan bagi membeli saham, bon, dan dana pelaburan yang boleh di dapati dari pasaran modal. Dana-dana ini berkembang secara amat drastik contohnya dana Universiti Michigan yang pada awalnya berjumlah USD106 juta dan selepas lima tahun ia berkembang kepada USD203 juta. Ini menunjukkan kejayaan pengurusan dana melalui strategi yang disebut diatas (Jeankins, 2008). McElhaney (2010) mendapati dua sumber pendapatan institusi pendidikan tinggi awam adalah geran dari kerajaan dan yuran pengajian dan pemerolehan dana endowmen adalah daripada wang tunai, aset kewangan, atau aset yang mempunyai aliran tunai bagi membiayai organisasi yang bukan berasaskan keuntungan. Penggunan aset pula adalah berbentuk bersyarat, bebas, dan separa bebas. Secara keseluruhan dana ini diperolehi daripada penyumbang-penyumbang yang menyumbang secara tetap (McElhaney, 2010).

Pengalaman Barat ini boleh diaplikasikan di Malaysia dengan menerapkan pelbagai instrumen penjanaan dana berlandaskan syariah dalam pengurusan dana wakaf pendidikan. Antaranya ialah mekanisme wakaf tunai (aset cair), aplikasi sistem muamalat Islam seperti instrumen takaful, pasaran modal Islam, sukuk mahupun penjanaan dana wakaf itu sendiri bagi menjana keuntungan yang tinggi dalam pengurusan dana wakaf di Malaysia (Syed Mohd Ghazali, 2012). Hal ini perlu dipastikan agar pembentukan dan pengurusannya selari dengan hukum Syarak (Siti Mashitoh, 2007). Norhazimah Che Hassan (2007) menekankan bahawa pengendalian dana berasaskan sistem kewangan Islam telah terbukti dapat diaplikasikan dengan efektif dan mampu membuahkan pulangan yang lumayan.

Antara institusi yang sudah memulakan aplikasi penjanaan dana seperti ini ialah UIAM melalui IIUM Endowment Fund yang telah menjana pulangan yang meningkat setiap tahun hasil daripada pelaburan wakaf yang dilakukan dan ini menjadikan tabung dana wakaf bersifat konsisten (Hafizah, 2013). USIM melalui Al-Abrar Waqf Fund pada tahun 2013 juga mengorak langkah untuk mendapatkan dana wakaf daripada Majlis Agama Islam Negeri Sembilan (MAINS) dan suntikan modal menggunakan prinsip musyarakah mutanaqisah (Mohamad Haji Alias et.al, 2013). Kejayaan badan korporat iaitu Kumpulan Waqaf An-Nur Berhad dan IIUM Endowment Fund (Malaysia) dan Warees Private Limited (Singapura) dalam pengurusan aset wakaf dengan aplikasi pendekatan berstruktur (structured approach) dalam pembangunan aset wakaf mereka telah memberi pulangan yang besar kepada dana wakaf (Norma et.al, 2013). Institusi ini sentiasa meneroka ruang dan peluang untuk menambahbaik pengurusan wakaf dalam usaha untuk memberikan manfaat yang lebih besar kepada masyarakat. Sebagai contoh, pendekatan yang diaplikasikan oleh WANCorp dalam pengurusan aset dan saham Johor Corporation (JCorp). WANCorp mengisytiharkan semua pendapatan yang diperolehi sebagai dividen dan akan diagihkan manfaatnya mengikut formula 70:25:5 di mana 70\% manfaat dipulangkan kepada JCorp untuk pelaburan semula dan pembangunan modal insan, 25\% dipulangkan kepada WANCorp untuk fisabilillah dan 5\% diagihkan kepada Majlis Agama Islam Johor. Formula ini membolehkan syarikat untuk mengekalkan kadar pertumbuhan dan menyumbang lebih banyak kepada wakaf di masa depan. 
Selain faktor penggunaan instrumen terbaik dalam menguruskan dana, faktor pihak atau individu yang menguruskan dana juga perlu diberi perhatian. Ahmad Furqon (2012) dalam kajian beliau mengenai wakaf di Indonesia, mendapati bahawa instrumen wakaf amat berpotensi dalam membangunkan pendidikan sekiranya ianya diuruskan oleh organisasi kebajikan yang berdikari, professional, boleh dipercayai, dan fokus. Pondok Pesantren Wakaf al-Mukhlisin dan Pondok Moden Darussalam Gontor (PMDSG) adalah antara institusi pengajian swasta berasaskan wakaf di Indonesia yang berjaya (Faishal, 2012). PMDSG misalnya dibiayai sepenuhnya melalui Badan Wakaf yang menjadi nadi penggerak kepada wakaf pendidikan di PMDSG tanpa bergantung kepada kerajaan atau mana-mana agensi tertentu. Konsep berdikari melalui pembangunan harta wakaf dan urus tadbir yang telus dan jujur, serta mempelbagaikan bentuk perniagaan telah berjaya mengeluarkan alumni yang terbukti dari segi kemampuan intelektual dalam masyarakat Indonesia (Mohamed Afendi, 2012).

Hidayatul Ihsan (2011) dalam kajiannya terhadap dua buah yayasan wakaf di Indonesia iaitu yayasan $\mathrm{ABC}$ dan XYZ untuk melihat kaedah pengurusan dan perakaunan wakaf serta peranan mutawalli dalam pengurusannya mendapati bahawa pengurusan Yayasan $\mathrm{ABC}$ adalah lebih efisien dan telus berbanding Yayasan XYZ. Ini adalah kerana, pengurusan di Yayasan ABC dilakukan oleh golongan professional yang komited terhadap agama Islam (Hidayatul Ihsan, 2011). Penemuan ini amat menarik kerana faktor kecemerlangan pengurusan sesebuah organisasi dikaitkan dengan pengamalan budaya kerja Islam yang jarang dikaitkan dalam mana-mana kajian. Nor 'Azzah Kamri (2010) menekankan perlunya setiap institusi yang mengurus wakaf supaya mengamalkan kod etika khas dalam pengurusan wakaf yang akan mewujudkan budaya kerja profesional dan institusi tersebut akan mencapai kecemerlangan sepertimana institusi terdahulu.

Pemasaran atau aktiviti mempromosi wakaf pendidikan juga seharusnya menjadi satu fokus penting bagi pengurus wakaf di IPT dan pihak berwajib. Ianya merupakan faktor kritikal bagi kejayaan pembangunan harta wakaf pendidikan negara. Kegagalan mengurus pemasaran dengan baik sudah pasti menyebabkan masalah kefahaman sempit masyarakat dan kurang sambutan mengenai wakaf pendidikan tidak dapat diatasi kerana kurangnya sumber maklumat (Ahmad Zaki, 2011). Beberapa kajian dan penulisan menyokong kenyataan ini. Sebagai contoh, kajian yang dilakukan terhadap warga UiTM mengenai wakaf secara umum mendapati tahap kefahaman mereka berada di tahap rendah dan kurang faham mengenai wakaf (Baharuddin, 2011). Malah, terdapat salah faham dalam kalangan masyarakat dalam memahami perbezaan antara sedekah dan sumbangan, serta pengurusan dana yang bercampur antara zakat dan wakaf menyebabkan minat masyarakat untuk berwakaf semakin menurun (Mohamad Akram Laldin, 2012).

Kefahaman wakaf dalam kalangan umat Islam di Malaysia dilihat masih di tahap rendah yang mana kebanyakannya masih belum memahami secara jelas mengenai konsep wakaf. Rata-rata memandang wakaf adalah tanah-tanah kubur atau tapak-tapak masjid sahaja (Noor Inayah, 2014) sedangkan konsep wakaf mempunyai skop yang amat luas meliputi penyediaan premis atau kompleks perniagaan, rumah kedai, kediaman dan sebagainya. Bahkan, wakaf dalam bentuk tunai dan saham masih belum popular dalam masyarakat kita (Mohamad Haji Alias et.al, 2013).

Hakikatnya, wakaf telah digunakan sebagai mekanisma pembangunan dalam sektor pendidikan, mengurangkan kadar kemiskinan, kesihatan, kebajikan, penyelidikan dan sebagainya sejak sekian lama dan ia merupakan kegiatan ekonomi yang merentasi sempadan (Ali Gom'ah, 2012). Namun, kebanyakan masyarakat pada hari ini memandang wakaf seolah-olah sudah tidak lagi relevan, malah terlalu ramai ahli masyarakat yang tidak mengenali konsep wakaf, justeru tidak mempunyai minat untuk berwakaf, lebihlebih lagi apabila terdapat kelemahan dalam pengurusan wakaf. Jika pun ada yang sedar, wakaf dilihat sebagai suatu amalan 'untuk mati' dan masyarakat tidak melihat wakaf sebagai sesuatu yang relevan atau mempunyai kaitan dengan keperluan hidup di zaman ini. Pemikiran sebegini didorong oleh amalan wakaf tradisional dalam masyarakat Malaysia yang dikaitkan dengan wakaf perkuburan, masjid, rumah 
anak yatim, dan seumpamanya yang dilihat sebagai amalan untuk bekalan di akhirat nanti (Muhammad Ali Hashim, 2012).

Harta wakaf juga perlu dikemaskini dan diurus dengan baik (Norhazimah, 2011). Dengan bantuan sistem teknologi maklumat moden, pengurusan maklumat harta wakaf pendidikan akan menjadi semakin mudah (Ahmad Zaki, 2005).

Pelbagai saranan yang dikemukakan ini boleh menjadi satu nilai tambah dan panduan kepada pengurus wakaf pendidikan IPT bagi memantapkan pengurusan mereka kerana sesuatu yang bernilai jika tidak diuruskan dengan efisyen tidak dapat dimanfaatkan untuk pembangunan umat (Ahmad Zaki, 2011). Sebagai contoh, Universiti Antarabangsa Albukhary (AiU) iaitu salah sebuah universiti di Malaysia yang mengamalkan konsep wakaf sejak 1996, telah dihentikan operasinya (ketika artikel ini ditulis pada Ogos 2014) ekoran masalah dalaman yang dihadapi oleh pihak pengurusan universiti tersebut (Astro Awani, 2014). Hal memberi petanda bahawa isu pengurusan wakaf pendidikan di institusi pengajian tinggi adalah satu perkara yang perlu diberi perhatian serius.

\subsection{ANALISIS SOROTAN LITERATUR}

Hasil sorotan literatur yang dijalankan, lima elemen utama telah dikenalpasti menjadi aspek utama perbincangan para sarjana dan ilmuan dalam memperkasakan institusi pendidikan wakaf di Malaysia iaitu:

1. Pengurusan Kewangan

2. Pengurusan Pemasaran

3. Pengurusan Pentadbiran

4. Pengurusan Tenaga Pakar

5. Pengurusan Maklumat

Pengurusan kewangan atau dana menjadi aspek tumpuan perbincangan para sarjana kerana ia merupakan tulang belakang kepada kejayaan sesebuah institusi pendidikan wakaf. Tanpa dana yang mencukupi dan konsisten, sesebuah institusi pendidikan wakaf pasti sukar untuk beroperasi dengan baik. Sumber kewangan yang bermasalah akan membawa kepada pelbagai masalah yang lain iaitu kekurangan fasiliti, sumber manusia yang terhad, kurang aktiviti promosi yang membawa kepada ketidakfahaman masyarakat tentang konsep wakaf pendidikan. Institusi pendidikan terutamanya institusi pendidikan tinggi tidak seharusnya bergantung kepada geran dan bantuan kerajaan dalam menguruskan operasi mereka. Sudah tiba masanya institusi pendidikan tinggi ini mempunyai dana sendiri dan memanfaatkan kewujudan pelbagai instrumen kewangan Islam di Malaysia hari ini untuk menjana pendapatan yang memberi pulangan besar kepada dana wakaf.

Aspek pemasaran atau promosi wakaf tidak kurang pentingnya dalam perbincangan para sarjana. Promosi yang kurang berkesan menyebabkan pengetahuan masyarakat mengenai wakaf tidak dapat dipertingkatkan, malahan tidak dapat membetulkan sebarang salah tanggapan mengenainya. Pihak pengurus wakaf IPT seharusnya memanfaatkan pelbagai medium pemasaran kontemporari seperti media elektronik, media cetak bahkan media sosial dalam usaha merancakkan aktiviti pemasaran seterusnya membuka luas pintu wakaf untuk disertai oleh ramai umat Islam.

Aspek-aspek lain yang turut diperbincangkan adalah mengenai urustadbir wakaf, tenaga pakar yang menguruskan wakaf, dan pengurusan maklumat atau aset wakaf. Pihak pentadbir wakaf sebagai pemegang amanah wakaf bertanggungjawab memelihara, memajukan, dan membangunkan semula hartaharta wakaf demi kemaslahatan ummah selaras dengan dasar dan hasrat pewakaf. Pengurusan pentadbiran wakaf jika tidak dijalankan dengan baik boleh memberi persepsi negatif kepada wakaf pendidikan. Skop pentadbiran ini meliputi aspek kecukupan kakitangan, keahlian kakitangan dalam pengurusan, kefahaman pengurusnya mengenai wakaf, kemudahan dalam pengurusan seperti penggunaan teknologi terkini bagi 
penyimpanan data wakaf dan sebagainya.Wakaf amat berpotensi dalam membangunkan pendidikan sekiranya diuruskan oleh organisasi yang profesional dan mengamalkan budaya kerja Islam yang sebenarnya. Cadangan agar setiap institusi yang mengurus wakaf perlu mengamalkan kod etika khas dalam pengurusan wakaf untuk mencapai kecemerlangan sebagaimana institusi terdahulu adalah amat wajar diberi perhatian.

Hasil sorotan literatur yang dibuat, orientasi perbincangan sarjana dan ilmuan mengenai wakaf pendidikan di Malaysia tidak lari daripada penemuan kajian oleh Ahmad Zaki latiff et.al (2005) yang mengemukakan lima cabaran dalam pengurusan wakaf pendidikan seperti yang dinyatakan di atas. Walau bagaimanapun, berdasarkan pemerhatian penulis, satu lagi aspek yang perlu diberi perhatian dalam pengurusan institusi wakaf pendidikan tinggi yang jarang dikupas ialah soal perundangan. Seperti yang dimaklumi, wakaf merupakan salah satu bidangkuasa Majlis Agama Islam Negeri. Sebagai contoh, Seksyen 32 Enakmen Wakaf Selangor secara jelas menyebut bahawa Majlis Agama Islam Selangor adalah pemegang amanah tunggal bagi wakaf yang bertanggungjawab untuk menguruskan hal ehwal wakaf mengikut perspektif syariah. Oleh itu, dalam soal mewujudkan wakaf pendidikan di IPT, pihak pengurus wakaf IPT mestilah mendapatkan kelulusan terlebih dahulu daripada Majlis Agama Islam Negeri masing-masing selaku pemegang amanah tunggal wakaf seperti mana termaktub dalam undangundang.

Kelulusan ini boleh diperolehi dengan mengadakan memorandum persefahaman sepertimana yang dilakukan oleh UKM (Anwar Sulong, 2013) dan UPM (Nurul Iman, 2013). Terbaru, USIM melalui A1Abrar Waqf Fund telah diluluskan permohonan mereka oleh Majlis Agama Islam Negeri Sembilan untuk dilantik sebagai Mutawalli. Pelantikan ini selaras dengan peruntukan dalam Enakmen Wakaf (Negeri Sembilan) 2005. Seksyen 5 menyebut, "Majlis hendaklah menjadi pemegang amanah tunggal bagi manamana mawquf yang terletak di dalam Negeri Sembilan". Walau bagaimanapun di bawah Seksyen 33, MAINS boleh melantik mana-mana individu atau ejen yang kompeten dan berkelayakan untuk menguruskan mana-mana mawquf termasuk hal ehwal pelaburannya. Dengan kelulusan ini, USIM mesti menyerahkan laporan pengurusan dan kewangan secara berkala mengenai pengurusan Al-Abrar Waqf Fund kepada MAINS dan pihak USIM juga mewujudkan akaun khas bagi tujuan wakaf bagi mengelakkan percampuran dengan akaun sedia ada (Mohamad Haji Alias et.al, 2013) .

Aspek perundangan ini perlu diperhalusi oleh pengurus wakaf IPT sebelum beroperasi agar tiada isu bidangkuasa timbul dan menjejaskan kepercayaan masyarakat terhadap kewibawaan sesebuah institusi pendidikan wakaf. Kelulusan MAIN ini diperlukan bukan sahaja untuk pemantauan, malah ianya membuka ruang kerjasama dan perbincangan yang lebih luas di antara pengurus wakaf IPT dan MAIN dalam usaha merancakkan lagi aktiviti wakaf pendidikan dan mencapai objektif yang digariskan. Dalam kajian yang dilakukan oleh penulis, IPT seperti UKM dan UPM telah pun memenuhi keperluan perundangan ini, begitu juga USIM. Walau bagaimanapun, IIUM Endowment Fund tidak pernah memohon kebenaran Majlis Agama Islam Negeri memandangkan mereka menggunakan perkataan 'endowmen' bukan 'wakaf'(Hafizah, 2013).

Perbincangan mengenai model terbaik yang boleh dirujuk dalam menguruskan wakaf pendidikan IPT juga kurang mendapat tempat dalam perbincangan para sarjana. Model ini penting untuk menjadi satu rujukan standard bagi pengurus wakaf IPT dalam operasi mereka meliputi aspek pemerolehan dana, pengembangan dana dan pengagihannya.

\subsection{PENUTUP}

Pelaksanaan wakaf pendidikan di IPT boleh diperhebatkan dengan pengurusan dana yang berkesan, perundangan yang kukuh, urustadbir yang baik, pemasaran yang berkesan, dan mengenalpasti model pengurusan wakaf yang sesuai untuk diaplikasikan. Untuk kajian akan dating, dicadangkan satu garis panduan khas bagi pengurusan wakaf pendidikan di IPT diwujudkandan satu model pengurusan 
wakaf dirangka untuk dijadikan rujukan semua IPT. Kemerosotan institusi wakaf dunia lantaran kelemahan pengurusan seperti yang berlaku kepada wakaf di Mesir perlu dijadikan sempadan bagi pengurusan institusi pendidikan wakaf di Malaysia, agar ianya tidak berkubur begitu sahaja. Sudah tiba masanya, wakaf pendidikan menjadi agenda besar umat Islam hari ini agar masalah keciciran anak bangsa dalam mendapatkan pendidikan lantaran kos pendidikan yang tinggi dapat di atasi, seterusnya usaha pembangunan modal insan yang berkualiti dunia dan akhirat dapat dilestarikan.

\section{Rujukan}

Abd. Shakor Borham. (2011). Pelaksanaan Pembangunan Wakaf Korporat Johor Corporation Berhad (JCorp): Satu Tinjauan. International Conference on Humanities. Pulau Pinang: Universiti Sains Malaysia.

Abdul Halim Sunny (2007). Dana Wakaf Untuk Pendidikan: Satu Tinjauan Awal. Jurnal Pengurusan JAWHAR, Vol. 1, No. 2.

Ahmad Zaki Latiff (2011). Pengurusan Harta Wakaf di Malaysia: Realiti dan Prospek. International Conference on Islamic Real Estate Education: A New Paradigm. Shah Alam: Universiti Teknologi Mara.

Ahmad Zaki Latiff (2005). Potensi Wakaf Dalam Menjana Kemajuan Islam. Prosiding Kolokium Zakat dan Wakaf (KOZAWA). Shah Alam: Universiti Teknologi Mara.

Ahmad Zaki Latiff \& Norhayati Hassan (2005). Potensi Wakaf Dalam Menjana Kemajuan Umat Islam. Dlm. Abdul Halim Ramli \& Ahmad Che Yaacob (Penyunting), Islam Hadhari: Pengukuhan Institusi Baitulmal dan Wakaf di Malaysia (pp. 99-107). Shah Alam: Universiti Teknologi Mara.

Ahmad Zaki Latiff, Norzaidi Mohd Daud \& Che Zuina Ismail. (2008). Pengurusan Harta Wakaf dan Potensinya Ke Arah Kemajuan Pendidikan Umat Islam di Malaysia. Jurnal Pengurusan JAWHAR, Vol. 2, No. 2.

Ahmad Zaki Latiff, et.al (2008). Wakaf Pengurusan dan Sumbangannya Terhadap Pendidikan Islam di Malaysia. Shah Alam: Pusat Penerbitan UPENA UiTM.

Ahmad Furqon (2012). Wakaf Sebagai Solusi Permasalahan Dunia Pendidikan di Indonesia. Jurnal alTaqaddum, Vol. 4, No. 2.

Ali Gom'ah (2012).Wakaf dan Kesannya Dalam Pertumbuhan Ekonomi. Kerja Kerja Seminar Wakaf Menjana Ekonomi, 16 Julai 2012, Putrajaya.

Al-Sarakhsi, Shams al-Din (1986). Al-Mabsut, Vol. 12. Beirut: Dar al-Ma'rifah.

Asmak Ab. Rahman (2009). Peranan Wakaf Dalam Pembangunan Ekonomi Umat Islam dan Aplikasinya di Malaysia. Jurnal SyariahVol. 17, Bil. 1.

Baharuddin Sayin \& S. Salahudin Suyurno (2011). Waqaf: Konsep, Model Pelaksanaan dan Cadangan untuk Pelaksanaan di Pusat Pengajian Tinggi. Dlm. Isu-Isu Semasa Mengenai Waqaf, Baharuddin Sayin (Penyunting). Shah Alam: Pusat Penerbitan Universiti (UPENA), UiTM.

Faishal Muhammad (2012). Pondok Pesantren Wakaf al-Mukhlisin: Sejarah dan Peranannya Terhadap Pendidikan Islam di Batubara (1997-2010) Sumatera Utara Indonesia. Disertasi Sarjana (Usuluddin) tidak diterbitkan, Universiti Malaya, Kuala Lumpur. 
Fayzee, Asaf A.A. (1974). Outlines of Muhammadan Law, Edisi 4. Delhi: Oxford University Press.

Hidayatul Ihsan \& Shahul Hameed Hj. Mohamed Ibrahim (2011). Waqf Accounting and Management in Indonesian Waqf institutions: The cases of two Waqf foundations, Jurnal Humanomics Vol. 27 No. 4.

Hisham Sabri (2007). Wakaf : Pengurusan dan Sumbangannya Terhadap Pendidikan Islam di Malaysia, Journal of Muamalat and Islamic Finance Research. Vol. 4 No. 1.

Ibn Manẓūr, Muhammad Ibn Mukarram (1990). Lisān al-‘Arab, Vol. 9, Beirut: Dār Sadr.

Ibn Qudamah, Muwaffiq al-Dīn Abū Muhammad (1972). Al-Mughnī, Vol. 6. Beirut: Dār al-Kitāb al'Arabì.

Mohammad Haji Alias, Fuadah Johari \& Hisham Sabri (2013). Waqf Development Financing in Higher Education: Challenges and the Way Forward Dlm. Islamic Perspective on Management: Contemporary Issues. Kuala Lumpur: YaPEIM Management Academy \& Jabatan Syariah dan Pengurusan APIUM.

Mohamed Azam Mohamed Adil, Mohd Afandi Mat Rani \& Mardhiyyah Sahri (2012). Transformation of Education For The Malays in Malaysia Through The Instrumen of Waqf: UiTM's Perspective, Kertas kerja $3^{\text {rd }}$ International Conference on Islam and Higher Education 2012, Kuantan Pahang.

Mohd Afendi Mat Rani (2011). Waqaf Pendidikan: Pengalaman di Pondok Moden Darussalam Gontor Ponorogo Indonesia. Dlm. Isu-Isu Semasa Mengenai Waqaf, Baharuddin Sayin (Penyunting), Pusat Penerbitan Universiti (UPENA), Universiti Teknologi Mara, Shah Alam Selangor.

Mohd Jelani b. Ramly (1998). Kajian Ke Atas Wakaf Bagi Tujuan Pendidikan Untuk Memenuhi Permintaan Sekolah Agama Bersepadu di Johor Bharu. Kertas Projek (Sarjana Muda) tidak diterbitkan, Universiti Teknologi Malaysia.

Monzer Kahf (2003). The Role of Waqf in Improving the Ummah Welfare, Kertas kerja dibentangkan dalam International Seminar on "Waqf as a Private Legal Body", Universiti Utara Sumatera, Indonesia.

Musțafā al-Khin (et.al) (2005). al-Fiqh al-Manhajī, Vol. 5, terjemahan Pustaka Salam, Kuala Lumpur: Pustaka Salam.

Noor 'Azzah Kamri (2010). The Role of Ethics in Waqf Management, Case of Jawhar, Jurnal Syariah, Vol. 18, No.3, Universiti Malaya, Kuala Lumpur.

Norhazimah Che Hassan (2007). Sistem Pengurusan Dana Cara Islam: Satu Penelitian, Jurnal Pengurusan JAWHAR, Vol.1 No. 2.

Norma Md. Saad \& et.al (2013), Involvement of Corporate Entities in Waqaf Management: Experiences of Malaysia and Singapore, Journal Asian Economic and Financial Review, 2013, 3(6)

Norsiah Sulaiman \& Farahdina Abdul Manaf (2009), Peranan Harta Wakaf Dalam Bidang Pembangunan dan Pendidikan Ummah: Fokus Dalam Bidang Perubatan, Jurnal Pengurusan JAWHAR, Vol. 3, No.1. 
Ramli, A. H. (2005), Pengurusan wakaf di Malaysia: Cabaran Dan Masa Depan, Dlm. Abdul Halim Ramli \& Ahmad Che Yaacob (Penyunting), Islam Hadhari: Pengukuhan Institusi Baitulmal dan Wakaf di Malaysia. Shah Alam: Universiti Teknologi Mara.

Razali Othman (2005), The Influences of Colonisation on the Perception and Practices of Wakaf, Jurnal IKIM. Kuala Lumpur: IKIM.

Siti Mashitoh Mahamood (2007), Pembentukan Dana Wakaf Menurut Perspektif Syariah dan Undangundang Serta Aplikasinya di Malaysia, Jurnal Syariah 15:2, Universiti Malaya, Kuala Lumpur.

Syed Mohd Ghazali Wafa bin Syed Adwam Wafa (2012), Pembangunan Wakaf di Institusi Pendidikan Tinggi, Kertas Kerja $3^{\text {rd }}$ International Conference on Islam and Higher Education, Kuantan, Pahang.

Astro Awani Online. Dilayari pada $12 \quad$ Ogos 2014 daripada http://www.astroawani.com/news/show/universiti-antarabangsa-albukhary-tutup-enam-pelajarsaman-universiti-33950.

Laman Web Dana Wakaf Ilmu, Universiti Putra Malaysia. Dilayari pada 13 Ogos 2014 daripada http://www.fund4knowledge.upm.edu.my/.

Laman Web Dana Wakaf Universiti Kebangsaan Malaysia. Dilayari pada 13 Ogos 2014 daripada http://www.waqaf.ukm.my/.

Laman Web Universiti Sains Islam Malaysia. Dilayari pada 13 Ogos 2014 daripada http://news.usim.edu.my/ms/berita-kampus/item/354-mengurus-universiti-melalui-pembiayaanwakaf.

Laman Web International Islamic University Malaysia (IIUM) Endowment Fund. Dilayari pada 13 Ogos 2014 daripada http://www.iium.edu.my/ief.

Laporan Tahunan 2013, Waqaf An-Nur Corporation Berhad. Dilayari pada 11 September 2014 daripada http://wancorp.com.my/wp-content/uploads/2014/08/Laporan_Tahunan_2013_WANCorp.pdf

Mohamad Akram Laldin (27 September 2012). Waqaf in Education Funding: The Experience of International Islamic University Malaysia in Managing Endowment (Waqaf) Fund, dilayari pada 13 Ogos 2014, daripada http://www.amanie-iconnect.com.

Monzer Kahf (t.t.), Waqf: A Quick Overview, hlm.6. Dilayari pada 21 Ogos 2014, daripada http://monzer.kahf.com/papers/english/WAQF_A_QUICK_OVERVIEW.pdf.

Muhammad Ali Hashim (9 Julai 2012), Wakaf Bukan Amalan Untuk Mati Sahaja. Dilayari pada 4 September 2014 daripada http://www.sinarharian.com.my/mobile/kolumnis/muhammad-alihashim/wakaf-bukan-amalan-untuk-mati-sahaja-1.64761.

Muhammad Ali Hashim, Sinar Harian Online bertarikh 23 Julai 2012, “Membuka Luas Pintu Wakaf”. Dilayari pada 9 September 2014 http://www.sinarharian.com.my/kolumnis/muhammad-alihashim/membuka-luas-pintu-wakaf-1.69235.

Noor Inayah Yaakub (13 Jun 2014), Mencorakkan Kejayaan Wakaf Pendidikan, Utusan Online. Dilayari $\begin{array}{llll}\text { pada } & 29 & \text { Ogos } & 2014\end{array}$ 
http://www.utusan.com.my/utusan/Rencana/20140613/re_03/Mencorakkan-kejayaan-wakafpendidikan.

Sinar Harian Online. Dilayari pada 13 Ogos 2014 daripada http://www.sinarharian.com.my/nasional/412245-peminjam-ptptn-tidak-buat-bayaran-balik-1.207152.

Sinar Harian Online. Dilayari pada $21 \quad$ Ogos 2014 daripada http://www.sinarharian.com.my/politik/penganalisis-pendidikan-percuma-tidak-jadikan-pelajarmalas-1.155661

Utusan Online. $\quad$ Dilayari pada $12 \quad$ Ogos $2014 \quad$ daripada http://www.utusan.com.my/utusan/Kampus/20121106/ka_01/Sesi-pertama-pengajian-UniversitiIslam-Malaysia-bermula-tahun-depan.

\section{Temubual}

Encik Anwar bin Sulong, Penolong Pendaftar Yayasan Canselor UKM pada 23 April 2013 jam 10.00 pagi di Pejabat Yayasan Canselor UKM.

Ustaz Nurul Iman bin Ibrahim, Ketua Seksyen Pengurusan Dana Wakaf Ilmu, Pejabat Bursar UPM pada 18 November 2013 jam 11.30 pagi di Pejabat Bursar UPM.

Temubual bersama Puan Hafizah Che Mat, Pengurus Unit Komunikasi Korporat IEF pada 24 April 2013 jam 2.30 petang IIUM Endowment Fund, Universiti Islam Antarabangsa, Gombak. 